\title{
Rhizomucor miehei Lipase-Immobilized Sodium Alginate Membrane Preparation and Usage in a Pervaporation Biocatalytic Membrane Reactor
}

\author{
F. Ugur Nigiz and N. Durmaz Hilmioglu* \\ Departments of Chemical Engineering, \\ Engineering Faculty, Kocaeli University, \\ 41380, Kocaeli, Turkey
}

doi: 10.15255/CABEQ.2016.2345

Original scientific paper

Received: January 9, 2016

Accepted: September 7, 2016

\begin{abstract}
In this study, Rhizomucor miehei lipase-coated alginate membrane was prepared and put in a biocatalytic membrane reactor to produce ethyl lactate from ethyl alcohol and lactic acid. Effects of the amount of coated lipase, reaction temperature and initial molar ratio on lactic acid conversion were investigated to evaluate the performance of the system. In order to compare the performance of the membrane reactor, the reaction was also carried out in a classical batch reactor by using lipase-immobilized membrane as a catalyst. The highest lactic acid conversion achieved was 0.63 in the membrane reactor at $50{ }^{\circ} \mathrm{C}$, while the lactic acid conversion was 0.37 in the batch reactor under the same operating conditions. After six reaction runs, approximately $90 \%$ of the lipase's catalytic activity was preserved in the membrane reactor.
\end{abstract}

Key words:

biocatalytic membrane reactor, lipase immobilization, ethyl lactate production, sodium alginate membrane, Rhizomucor miehei

\section{Introduction}

Lipases are called "green agents" as they are able to catalyze numerous of chemical reaction in mild operating conditions with effective energy usage. They provide direct conversion of reactant to the desired product with less side reaction ${ }^{1,2}$. However, there are some drawbacks when using lipase in all reactions. Due to the high costs of producing lipases from their natural sources, they should be recovered from the homogeneous reaction media and reused. Extraction, membrane filtration, and ultrafiltration techniques can be used for lipase recovery $^{3,4}$. The viscosity of the reaction media directly affects efficiency of the enzyme's recovery ${ }^{3}$. Immobilization of lipases on an appropriate support is another way of simplifying the recovery of lipase from reaction media ${ }^{5,6}$. The immobilization method facilitates protection of lipase activity ${ }^{5-7}$. For an effective immobilization, it is essential to provide the appropriate immobilization conditions. Temperature, $\mathrm{pH}$, and solvent concentration of the immobilization media directly affect the efficiency. Besides the operating conditions, selection of immobilization support material is critical. According to the type of lipase or conditions in the reaction, inorganic materials such as zeolites or polymers may be

"Corresponding author. Phone: +90 26230335 45;

E-mail address: niluferh@kocaeli.edu.tr used. Because of their easily forming ability, polymeric materials are frequently preferred as supports. Polymeric material can easily be produced as lipase-encapsulated beads, thin film, or membrane.

In many aspects, immobilization of lipases on a membrane support contributes to increasing the overall reaction yield. Lipase can be incorporated into the spongy structure of an ultrafiltration membrane or it can be encapsulated by a membrane material and formed as a thin film ${ }^{8}$. The membrane immobilization technique improves the reusability of lipase under the different operating conditions. This method prevents the inhibitory effect of reactant or product on lipase by isolating the lipase from the product-reactant medium. The lipase-immobilized membrane provides a controlled contact of reactants with lipase. Therefore, lipase activity can be preserved $^{9-11}$. Moreover, it is possible to incorporate a desired amount of lipase on the membrane support. Immobilization efficiency is directly related to determination of appropriate lipase loading. Considering all of these advantages, it is possible to achieve an energy-efficient enzymatic reaction by using the membrane immobilization method.

In the literature, sponge type ultrafiltration and microfiltration membranes are preferable compared to inorganic membranes ${ }^{12-14}$. Inorganic materials show high resistance to chemicals and can be used at high temperatures. However, they are brittle and the mass transfer rate of the substrate within inor- 
ganic particles can be quite slow. Although polymeric membranes are more vulnerable, they are cheap and can easily be modified. The immobilization of lipase on a polymeric membrane is very effective. Because of the molecular structure of polymeric materials, it is possible to orient the lipase in the desired conformation. For this purpose, natural and synthetic polymers can be used due to their good adaptation and biological properties ${ }^{15,16}$.

Sodium alginate is a natural polysaccharide produced from brown seaweed. Because of its non-toxicity and mild gelling properties, it is frequently preferred as a lipase support material. In the literature, there are many studies related to sodium-alginate-coated lipase in different forms. In most of these studies, alginate was used in bead form $^{17-19}$. It has been reported that the alginate-entrapped lipase preserved about $95 \%$ of its activity after being used 10 times $^{18}$. However, it was also reported that the activity of bead form alginate-coated lipase is relatively low compared to the free ones because of the mass transfer limitation. Therefore, it is important to arrange the coating thickness. Additionally, it is required to improve the swelling behavior of membrane in aqueous reaction media. For this purpose, a cross-linking procedure is applied ${ }^{19-23}$. Recently, a thin film polymer-coated lipase on an ultrafiltration membrane has been reported to eliminate the mass transfer limitation ${ }^{8,21}$.

The membrane bioreactor is a reactor type in which a lipase-immobilized membrane is used as a heterogeneous catalyst. The main function of the membrane catalyst is to ensure easy separation of the lipase from the product and keeping the lipase on the membrane surface ${ }^{24-27}$. The biocatalytic membrane reactor is another enzymatic system that combines the reaction and product purification into one stage by using a biocatalytic membrane such as lipase-coated membranes. While the reaction occurs at the lipase-immobilized layer (catalytic layer) of the membrane, the selected compound is removed by the selective layer of the membrane ${ }^{16,28}$. In this type of reactor, quality and quantity of the driving force changes according to the structure of the membrane. If the separation occurs according to the concentration gradient by using a dense membrane, then the reactor can be defined as a "pervaporation-aided biocatalytic membrane reactor (PVBCMR)"'29.

In this study, a lipase-catalyzed esterification reaction between ethanol and lactic acid was performed in a biocatalytic membrane reactor. In the literature, several studies related to the enzymatic synthesis of ethyl lactate have been reported ${ }^{30-32}$. Chemically catalyzed ester production in a membrane reactor was also reported in the literature earlier ${ }^{3-35}$. However, lipase-catalyzed ethyl lactate pro- duction in a membrane reactor has been rarely reported $^{8,36}$. In most of these studies, lipase has been used as a free catalyst or as immobilized beads in a classical reactor. Findrik et al. studied the ethanol-lactic acid esterification reaction by means of a commercial immobilized enzyme (immobilized Candida antarctica B) and obtained 0.59 lactic acid conversion within 5 hours in a batch reactor ${ }^{37}$. Koutinas et al. studied the same reaction with a Novazyme 435 immobilized enzyme and reported 0.33 lactic acid conversion in a batch reactor ${ }^{38}$.

In the present study, a non-porous lipase-immobilized membrane was put in a membrane reactor to produce ethyl lactate. This system can be defined as a green and environmentally friendly process because of the lower energy consumption, one-stage reactive separation ability and cost efficiency. This process was selected to obtain a green solvent by using sustainable chemical agents, reactants, and polymers. Ethyl lactate is known as a green solvent due to its non-toxicity, non-ozone-depleting and biodegradable properties. It is also produced from bio-based feedstock ${ }^{39}$. Sodium alginate was selected as the polymer due to its well-known adoption property with lipase $\mathrm{e}^{40,17-19}$. Lipases were immobilized on alginate surface by entrapment and cross-linking technique reported in the previous study $^{36}$. The reaction capability of immobilized lipase was evaluated as a function of lactic acid conversion. The effect of the lipase amount on the membrane surface, reaction temperature and initial molar feed ratio on acid conversion were investigated. The selective separation properties of the membrane were also investigated as a function of flux and separation factor. In order to evaluate the efficiency of this system, the reactions were also carried out in a batch reactor with membrane-immobilized lipase (as a heterogeneous catalyst) and free lipase (as a homogeneous catalyst) under the same operating conditions.

\section{Materials and methods}

\section{Materials}

Lipase obtained from Rhizomucor miehei (RM) was kindly supplied by Novozymes, Turkey. Sodium alginate polymer, glutaraldehyde, lactic acid (80 $\%$ purity), ethyl alcohol (97\% purity), ethyl lactate (99\% purity) were purchased from Aldrich Chemicals.

\section{Membrane preparation}

In this study, a biocatalytic membrane was prepared as two-layered. For the first layer (bottom layer), a dense sodium alginate membrane was pro- 
duced to separate the water selectively. For the second layer, lipase was entrapped with a very diluted alginate solution and cast onto the first selective layer to catalyze the esterification reaction between ethyl alcohol and lactic acid. The solution-casting technique was used to prepare this two-layered lipase-immobilized membrane. With this method, it was possible to prepare a small amount of membrane for laboratory applications and the procedure based on the controlled evaporation of polymeric solution $^{41}$. For the preparation of the selective first layer, a mixture of $3.5 \mathrm{wt}$. \% of alginate and water was prepared and stirred for 24 hours at room temperature. After a homogeneous solution had been obtained, it was poured into a glass Petri dish and allowed to evaporate at room temperature. The average thickness of this layer was about $50 \mu \mathrm{m}$, and the membrane area was approximately $110 \mathrm{~cm}^{2}$.

For the preparation of the lipase loaded-layer, the desired amount of RM lipase was encapsulated with a dilute alginate-water solution and cast onto the first layer. This layer was prepared as very thin (approximately $8 \mu \mathrm{m}$ ) to prevent the mass transfer limitation between the substrate and lipase. The two-layered membrane was oven-dried in the oven at $50{ }^{\circ} \mathrm{C}$ rapidly for two hours. The membrane was cross-linked in a bath containing 1 vol. \% glutaraldehyde, 1 vol. \% HCl, 73 vol. \% acetone and 25 vol. \% water to prevent dissolving of the membrane in aqueous reaction media. Cross-linking with glutaraldehyde also contributed to stabilizing the lipase on the membrane surface.

\section{Membrane characterization}

Lipase distribution on the membrane matrix was analyzed by means of a JEOL JSM-6335 F Field Emission Scanning Electron microscope. Surface properties of pristine and lipase-loaded membranes were also analyzed using Quesant EIU Trapping mod AFM device.

\section{Esterification}

The biocatalytic membrane reactor (BCMR) is a combination of a reactor and a pervaporative separation system in one stage. In the present study, the biocatalytic membrane was put inside the reactor. The reactor had $40 \mathrm{~mL}$ constant volume with 19.625 $\mathrm{cm}^{2}$ effective membrane area. The BCMR was settled inside an oven. The system was kept at constant temperature. In order to minimize the mass transfer problem, a mechanical stirrer was connected to the membrane reactor. The upstream side of the membrane was kept at atmospheric pressure and $30 \mathrm{mbar}$ pressure was applied on the permeate side. The configuration of the system is given in Figure 1.

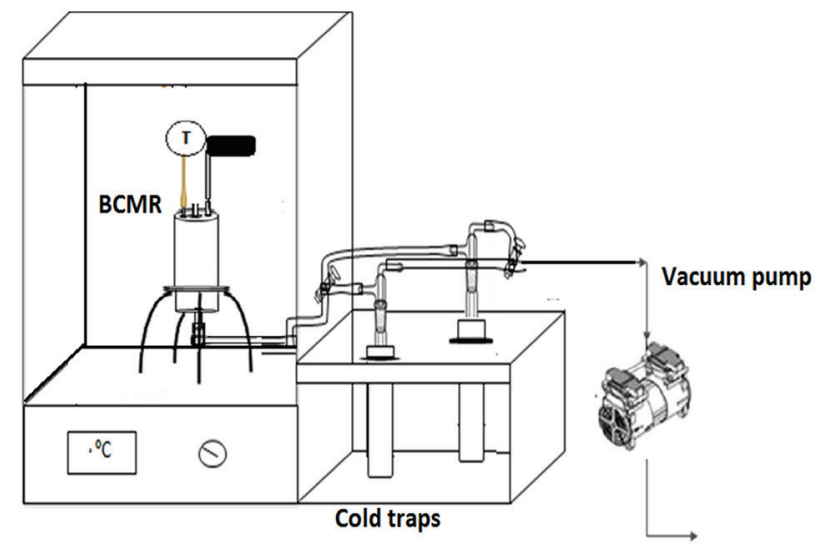

Fig. 1 - Experimental BCMR set-up

This study focused on the increasing of the lactic acid conversion by simultaneously removing the water along with ethyl lactate. In the BCMR, when the reaction occurred on the top surface of the membrane, water was selectively separated from the reaction media by the bottom layer of the non-porous biocatalytic membrane.

The effect of lipase loading, alcohol-to-acid feed molar ratio $(\mathrm{M})$, and operating temperature on acid conversion were investigated to obtain the catalytic activity of the system. In addition, flux and separation factor were determined to evaluate the selective separation character of the membrane. The amount of lipase to be used for immobilization was determined as $0.5 \mathrm{~g}, 1 \mathrm{~g}$ and $1.25 \mathrm{~g}$. The lipase loaded membranes were designated according to the total amount of lipase on the membrane surface. For example, RM0.5 represents $0.5 \mathrm{~g}$ of lipase per $110 \mathrm{~cm}^{2}$ membrane area.

The reactions were carried out at 30,40 and 50 ${ }^{\circ} \mathrm{C}$. The alcohol-to-acid initial molar ratio was designated as $\mathrm{M}$ and the molar ratio was determined as $\mathrm{M}=1(0.3 \mathrm{~mol}$ ethyl alcohol and $0.3 \mathrm{~mol}$ lactic acid), $\mathrm{M}=3(0.48 \mathrm{~mol}$ ethyl alcohol and $0.16 \mathrm{~mol}$ lactic acid), and $\mathrm{M}=6$ (0.6 mol ethyl alcohol and $0.1 \mathrm{~mol}$ lactic acid). In order to understand the system efficiency, the reactions were also carried out under the same operating conditions in the batch reactor with free and immobilized lipases. The biocatalytic membranes were cut into small pieces and used as an immobilized catalyst in the batch reactor. Additionally, the same free lipase was used in the batch reactor to react with substrate without immobilization under the same operating conditions. In the case of the BCMR and batch reactor with immobilized enzyme, the conversion results were recorded in hourly intervals. In the case of the batch reactor with free lipase, only the final conversion was recorded to compare the catalytic activity and productivity of lipase with the other reactors. 


\section{Calculation}

The reactions were carried out for six hours in all reactors. At hourly intervals, $2 \mu \mathrm{L}$ reaction samples were taken from the reactor and the traps, analyzed using gas chromatography (GC) to determine the compositions of components. In this study, thermal conductivity detector (TCD) and HP-FFAP column equipped with GC (Agilent 7980) was used. The carrier gas was nitrogen. Detector temperature was arranged to $280{ }^{\circ} \mathrm{C}$, oven temperature was 220 ${ }^{\circ} \mathrm{C}$, and injector temperature was $240{ }^{\circ} \mathrm{C}$. The GC method was also used to determine the permeate compositions in cold traps at hourly intervals.

The reaction samples were also analyzed by a titration method for determining the lactic acid conversion composition. Free acid percentage of lactic acid in the reaction media was determined, and the conversion was also calculated as reported in the literature ${ }^{42,43}$. For this purpose, $0.1 \mathrm{~g}$ reaction sample was taken from the reactor and titrated with 0.1 molar potassium hydroxide. Before the experiments, initial free lactic acid purity was also determined. Although the purity was mentioned as $80 \%$ lactic acid on the label of the chemical, the acid content was determined as $73-75 \%$ by using titration method. Additionally, the water content in the initial lactic acid was determined as 25 wt. \% by means of Karl Fischer Titration. The water content in the initial lactic acid was determined using TitroLine 7500KF Model Karl Fischer Titration.

Flux $(J)\left(\mathrm{kg} \mathrm{m}^{-2} \mathrm{~h}^{-1}\right)$ was calculated from the measured weight of permeate sample, as shown in Eq. 1

$$
J=\frac{W_{p}}{t \cdot A}
$$

The water separation factor $(\alpha)$ was calculated from Eq. 2

$$
\alpha=\frac{Y_{a} / X_{a}}{Y_{b} / X_{b}}
$$

Where $W_{p}$ is the weight value of permeate stream (kg), $t^{p}$ is the time (h), $A$ is the effective membrane area $\left(\mathrm{m}^{2}\right), Y_{a}$ and $X_{a}$ are mass fractions of water in the permeate and the feed respectively. $Y_{b}$ and $X_{b}$ are the mass fractions of other compounds in the permeate and the feed respectively ${ }^{44-46}$. The compositions of permeate and retentate streams were measured by means of GC.

\section{Results and discussion}

\section{Morphology and surface characteristics of the biocatalytic membrane}

Figures 2 and 3 represent the morphological structures of pure and coated alginate membranes. SEM images are shown in Figure 2. Figure $2 \mathrm{a}$
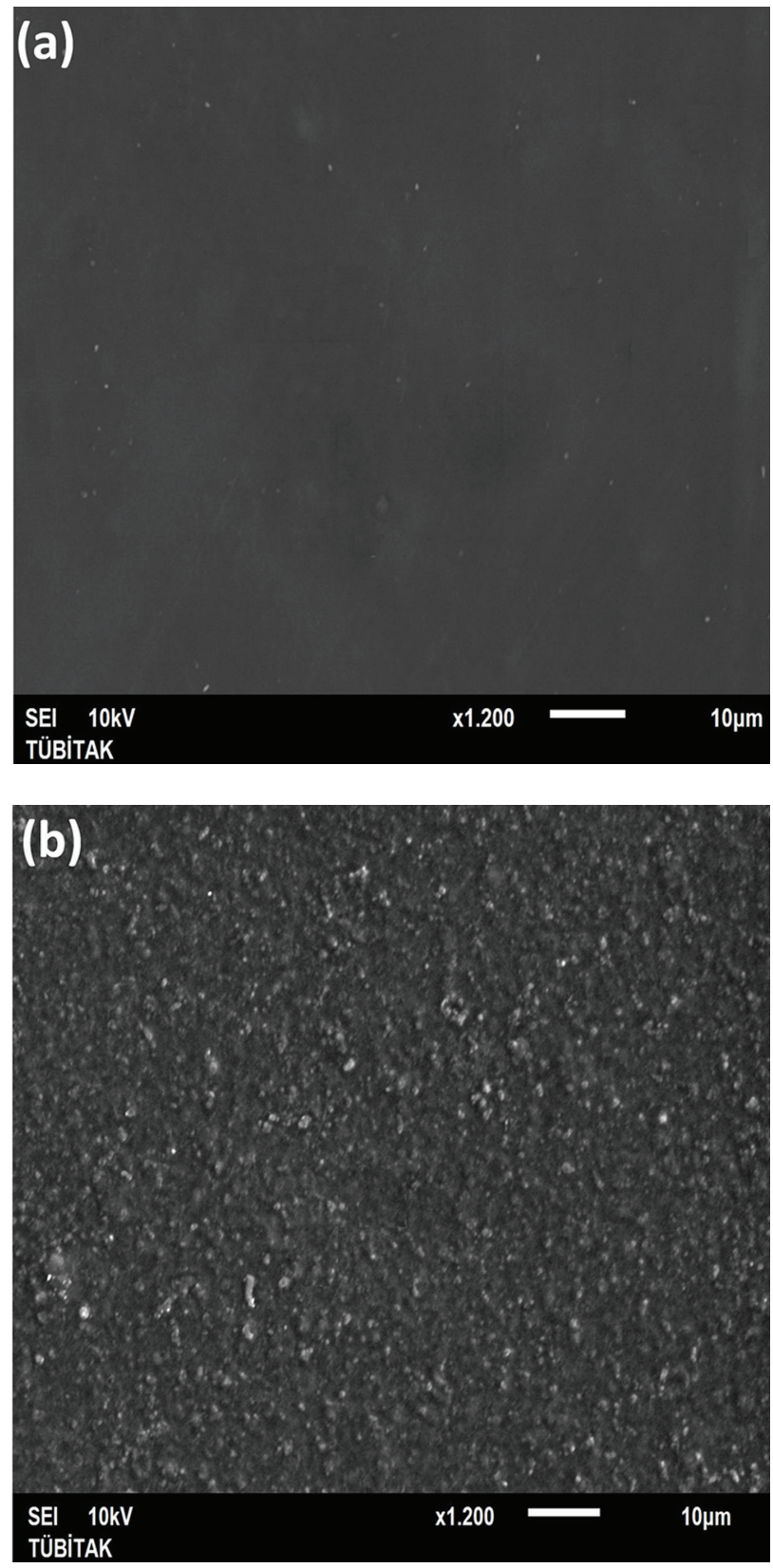

Fig. 2 - Surface SEM images of pristine (a) and lipase-loaded (b) sodium alginate membrane

shows the surface of the pristine sodium alginate membrane, and in Figure $2 b$, the light phase shows the lipase particles.

As can be observed in Figure 2b, the lipases were well distributed on the membrane surface, which was proved by the AFM test. The AFM images are given in Figure 3. While Figure 3a represents the $3 \mathrm{D}$ image of the pristine membrane surface, Figure $3 b$ shows the lipase-immobilized membrane layer with an equal lipase size. Hence, it could be concluded that the substrates could be allowed to react effectively on the entire surface of the membrane. 

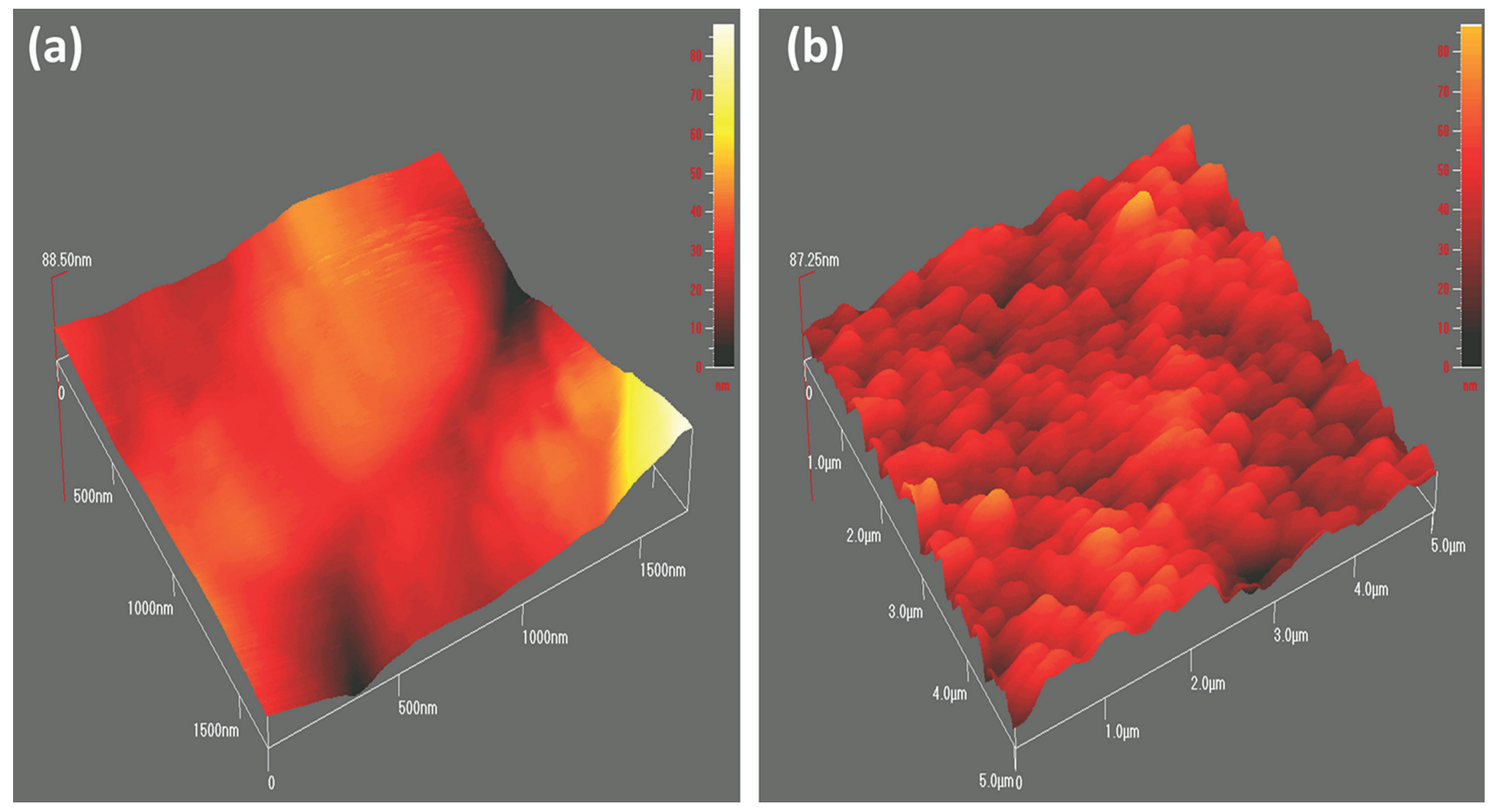

Fig. 3 - Pristine (a) and lipase-loaded (b) AFM images of sodium alginate membrane

Table 1 - Pervaporative separation results of membranes

\begin{tabular}{c|ccc|c|c|c}
\multicolumn{3}{c}{$(M=1)$} \\
\hline $\begin{array}{c}\text { Lipase } \\
\text { loading } \\
(\mathrm{g})\end{array}$ & \multicolumn{3}{|c|}{ Flux $\left(\mathrm{kg} \mathrm{m}^{-2} \mathrm{~h}^{-1}\right)$} & \multicolumn{3}{|c}{ Separation factor } \\
\cline { 2 - 7 } & $30{ }^{\circ} \mathrm{C}$ & $40{ }^{\circ} \mathrm{C}$ & $50{ }^{\circ} \mathrm{C}$ & $30{ }^{\circ} \mathrm{C}$ & $40{ }^{\circ} \mathrm{C}$ & $50{ }^{\circ} \mathrm{C}$ \\
\hline 0.5 & 0.06 & 0.09 & 0.16 & 14.91 & 4.96 & 3.21 \\
1 & 0.03 & 0.12 & 0.18 & 18.60 & 5.31 & 3.47 \\
1.25 & 0.10 & 0.16 & 0.17 & 4.32 & 4.58 & 3.86 \\
\hline
\end{tabular}

\section{Effect of lipase loading on acid conversion}

The total amounts of lipase to be incorporated into the membrane surface were determined according to the lipase-membrane interaction. Before specifying the total amount of lipase, optimization tests were applied. Alginate was a bio-based polymer and it was completely compatible with lipases $^{40,47}$. As can be seen in Figure 4, the highest conversion values were obtained with RM1 at all temperatures when $M=1$. A decrement trend was observed with RM 1.25 due to the overloading lipase ratio. Active sites of lipases and reaction capability might be prevented by the agglomeration ${ }^{28}$.

According to the lipase ratio, the separation performance of biocatalytic membrane is given in Table 1. At all temperatures better flux and selectivity values were achieved by RM 1 membrane.

Both the reaction and separation results confirmed that the RM1 was an appropriate biocatalytic membrane to determine the effect of other process parameters on system performance.

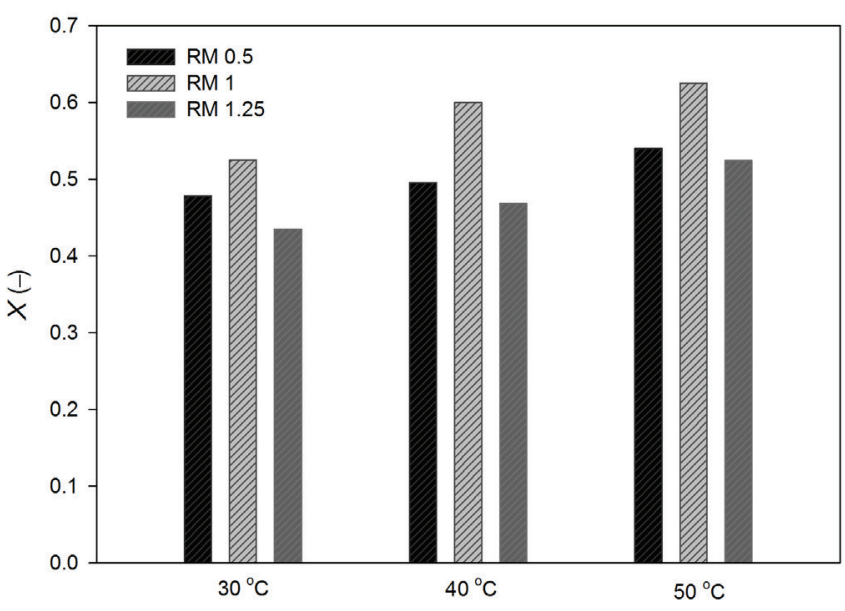

Fig. 4 - Effect of lipase loading on conversion ( 0.3 mol ethyl alcohol: 0.3 mol lactic acid)

\section{Effect of temperature on acid conversion and separation performance}

Before the effect of temperature was determined in the BCMR and batch reactor, many preliminary experiments had been done. Because of the protein nature of lipase catalyst, a very sharp decline in conversion results was obtained at the temperature above $50{ }^{\circ} \mathrm{C}$. Hence, the upper temperature limit was determined as $50{ }^{\circ} \mathrm{C}$ for this reaction. Additionally, it was observed that the productivity of lipase in the batch reactor was very low compared to the BCMR at temperatures below 30 ${ }^{\circ} \mathrm{C}$. Therefore, the lower temperature limit for this study was determined as $30^{\circ} \mathrm{C}$. 
The results of the batch reactor with immobilized lipase catalyst and the BCMR are presented in Figure 5. The figure shows information about the effect of temperature on lactic acid conversion. According to Arrhenius equation in an endothermic reaction, the reaction rate increased with temperature. Hence, the conversion increased in the BCMR and the batch reactor as expected. Compared to the batch reactor, the results of the BCMR were higher due to the continuous removal of water from the reversible reaction medium. This result was expected according to the "Le Chatelier Principle". Moreover, the inhibitory effect of products on lipase could be eliminated by removal of water from the reaction media. While a conversion of 0.37 was obtained in the batch reactor, an 0.63 lactic acid conversion was achieved in the BCMR. Therefore, it was observed that the reaction yield could be enhanced without changing the reaction conditions of the reactor, without increasing the amounts of catalyst and without the addition of chemicals. Because of the inhibitory effect of water on lipase, the extent of water could also negatively affect the lipase-catalyzed reaction. In the BCMR, the removal of water from the reaction medium ensured preservation of lipase activity ${ }^{48,49}$.

Flux is the amount of compounds permeated through the membrane per time and unit membrane area. In this study, total flux has been defined instead of a single component flux. It is possible to calculate the partial flux of each components by using separation factor data. If the flux is the amount of permeated component, then it is important to take into account the effects of membrane structure, interaction between membrane-component and component-component to determine the flux behavior. Therefore, the flux exchange should be examined in terms of the membrane material and the solution chemistry separately. The same theory is also valid for the separation factor. When the results in Figure 6 are evaluated depending on the membrane structure, temperature is directly associated with membrane substance.

Membrane permeability enhanced with temperature due to the increasing chain mobility and free spacing of the polymeric material ${ }^{50-52}$. Moreover, the diffusion rates and the vapor pressure of component increased, and the driving force between the sides of the membrane increased with temperature $^{53}$. As a result, flux enhanced as expected. However, almost all parameters that increased the flux also decreased the separation factor. For example, a non-selective separation occurred due to the expanded polymer chain. Hence, large chain structure allowed the passage of larger molecules, such as alcohol and ester together with water and reduced the separation factor, as shown in Figure 6. 


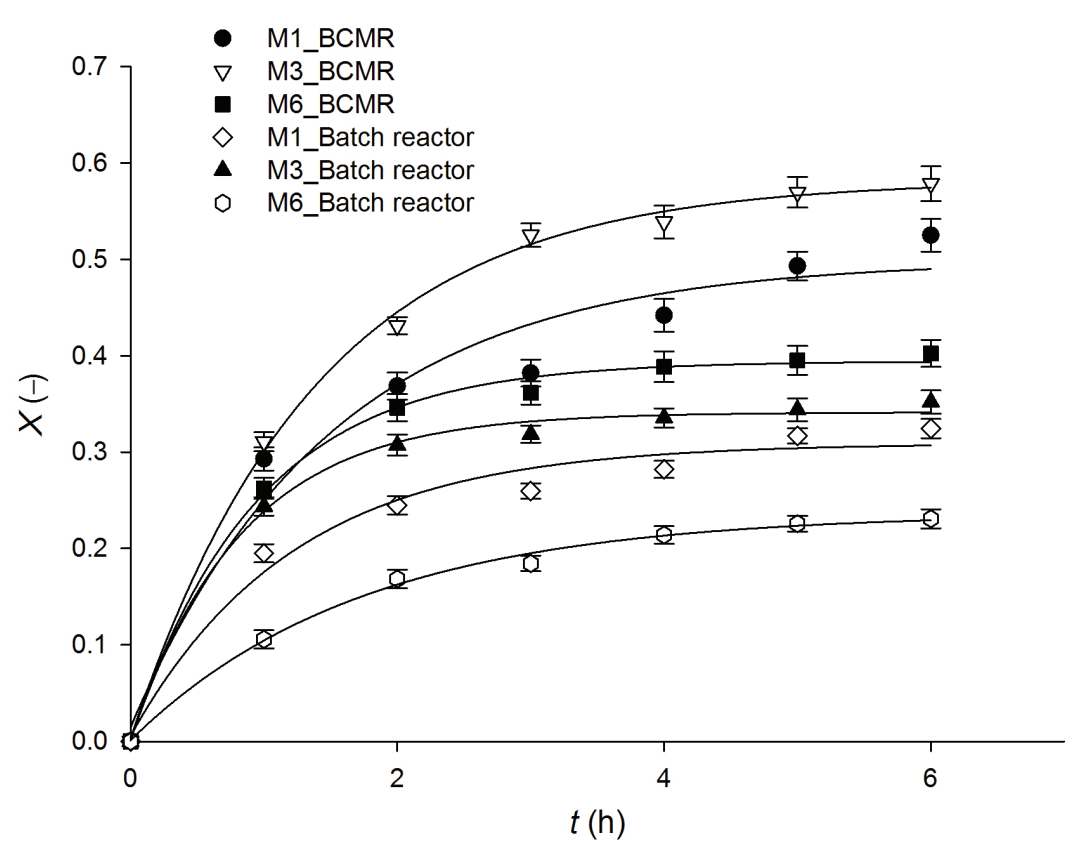

Fig. 7 - Effect of feed molar ratio on lactic acid conversion $\left(30^{\circ} \mathrm{C}, \mathrm{RM} 1\right)$

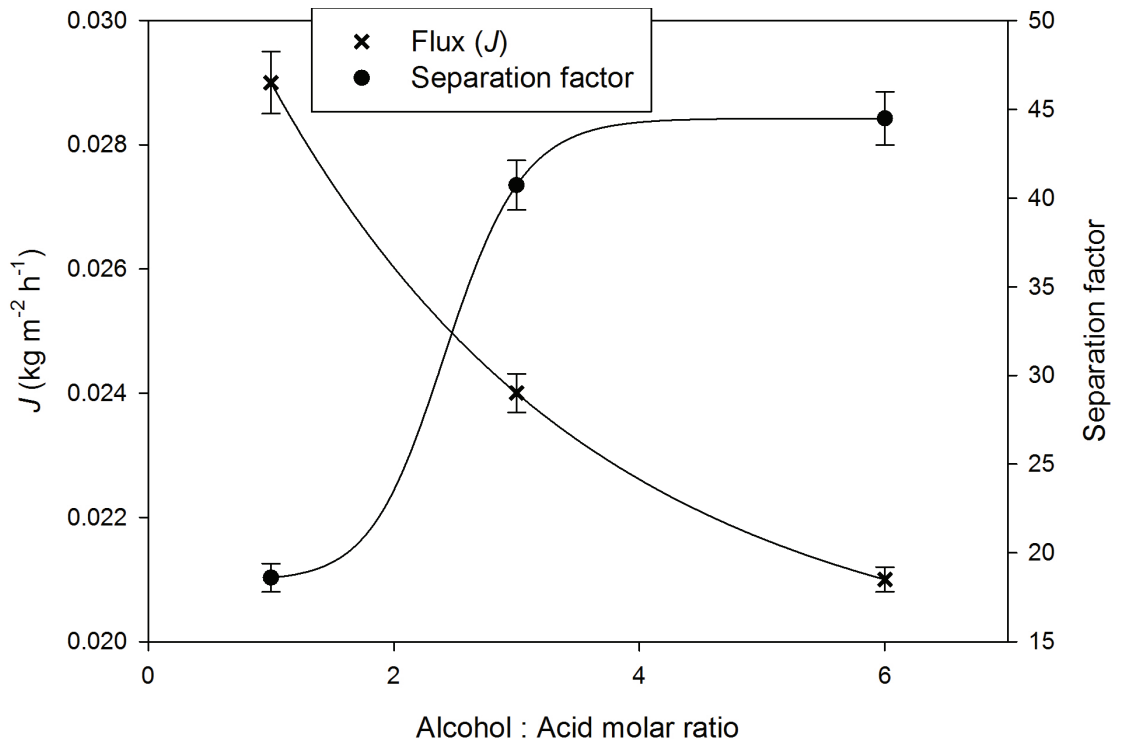

Fig. 8 - Effect of feed molar ratio on separation performance $\left(30^{\circ} \mathrm{C}, \mathrm{RMI}\right)$

Figure 7 indicates the effect of feed molar ratio on acid conversion. Experiments were carried out with RM1 at $30{ }^{\circ} \mathrm{C}$. While 0.58 lactic acid conversion was obtained with $\mathrm{M}=3$ feed molar ratio in BCMR, 0.35 conversion was achieved in the batch reactor. As seen in Figure 7, a significant decline was observed with $M=6$ molar ratio. This could be explained by the inhibitory effect of substrate on lipase. Therefore, it was important to determine the optimum molar ratio in order to enhance reaction yield.

Flux and separation factor changes can be seen in Figure 8 . Flux was an important factor for defining the membrane productivity. In pervaporation-aided BCMR, a non-porous membrane was used. Therefore, the importance of flux became a critical parameter to determine the system efficiency. As mentioned previously, the alginate was a hydrophilic polymer and, the existence of water caused a swelling through the intermolecular spaces of the polymeric membrane $^{54,55}$. Hence, flux values increased with increasing water content in the reaction medium. Flux was directly related to the reaction yield and the conversion. As the conversion increased in the reactor, water was generated, the space between the polymer chains expanded and flux increased again. Meanwhile, flux and conversion were dependent on each other.

As can be seen in Figure 8, higher flux was obtained when the

\section{Effect of feed molar ratio on acid conversion and separation performance}

The initial feed molar ratio was another determinant factor for the performance of this reaction. Before the appropriate initial molar ratios were selected, some preliminary experiments had been done. Better results were obtained when the alcohol-to-acid molar ratio was three. After that point $(\mathrm{M}=4, \mathrm{M}=5)$, conversion slightly decreased, and a drastic decrement was observed when the molar ratio was six in all operating conditions. Hence, the three significant points were selected: minimum reaction limit $(M=1)$, maximum conversion $(M=3)$, and significant decrement $(\mathrm{M}=6)$. alcohol-to-acid molar ratio was one. The initial lactic acid included approximately $20-25 \mathrm{wt}$. \% of water (measured by Karl Fischer Titration). The water concentration of $\mathrm{M}=1$ was higher than $\mathrm{M}=3$ and $\mathrm{M}=6$. Although conversion values and produced water amount of $\mathrm{M}=3$ were higher than the result obtained with $M=1$, the total water content of $M=$ 3 was lower than $\mathrm{M}=1$.

The same explanation was also valid for $\mathrm{M}=6$. Therefore, flux values rating could be shown as M1 $>\mathrm{M} 3>\mathrm{M} 6$.

The separation factor is another major value for defining the selective character of the membrane. However, separation factor and flux values show a 
Table 2 - Comparison of conversions of all reactor types

\begin{tabular}{c|c|c|c|c|c|c|c}
\hline $\begin{array}{c}\text { Temperature } \\
\left({ }^{\circ} \mathrm{C}\right)\end{array}$ & $\begin{array}{c}\text { Alcohol: Acid } \\
\text { molar ratio }\end{array}$ & $\begin{array}{c}\text { Enzyme } \\
\text { loading }(\mathrm{g})\end{array}$ & $\begin{array}{c}\text { Batch reactor } \\
\text { conversion } \\
\text { (Immobilized } \\
\text { lipase) }\end{array}$ & $\begin{array}{c}\text { Immobilized } \\
\text { lipase activity } \\
\text { (mol EL g }{ }^{-1} \\
\text { lipase) }\end{array}$ & $\begin{array}{c}\text { Batch reactor } \\
\text { conversion } \\
\text { (Free lipase) }\end{array}$ & $\begin{array}{c}\text { Free lipase } \\
\text { activity } \\
\text { (mol EL g-1 } \\
\text { lipase) }\end{array}$ & $\begin{array}{c}\text { BCMR } \\
\text { conversion }\end{array}$ \\
\hline 30 & 1 & 1 & 0.32 & 0.64 & 0.32 & 0.63 & 0.53 \\
40 & 1 & 1 & 0.34 & 0.69 & 0.33 & 0.67 & 0.60 \\
30 & 1 & 1 & 0.37 & 0.74 & 0.36 & 0.71 & 0.63 \\
30 & 3 & 1 & 0.35 & 0.70 & 0.37 & 0.72 & 0.58 \\
\hline
\end{tabular}

reverse effect on one another frequently. Because of the flexible polymer chains that are expanded by membrane swelling, flux increases and separation factor decreases. The degree of swelling is a necessary property for membrane material. However, the excess amount of swelling causes a non-selective permeation of compounds ${ }^{5,55}$.

In this study, sodium alginate was used as membrane matrix, which is known as a quite hydrophilic membrane material. When the water content increased on the top surface of the membrane, the swelling degree increased and separation factor decreased. It is clear from Figure 8 those of the separation factor values of $M=6$ were higher than the others. While the initial alcohol ratio in the

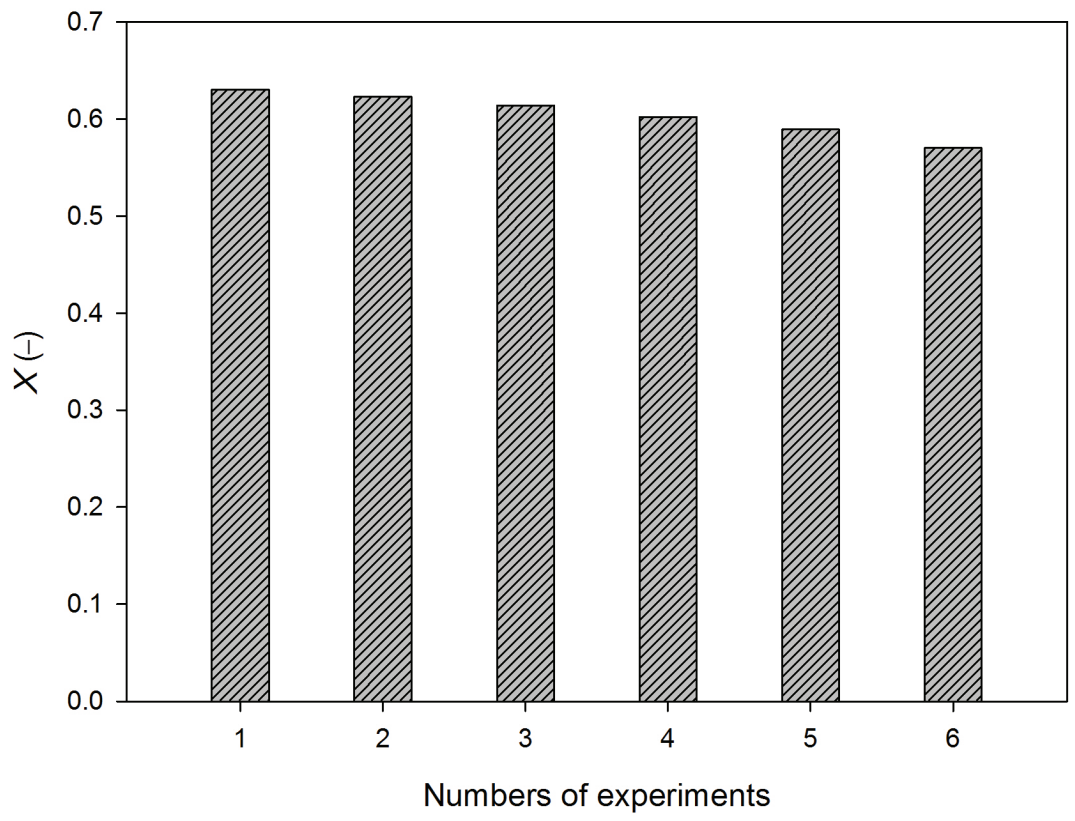
reaction increased, the total water

Fig. 9 - Reusability experiment of lipase-coated membrane in $B C M R\left(50{ }^{\circ} \mathrm{C}\right.$, $R M 1, M=1$ )

percentage decreased. Hence, as mentioned previously, the swelling degree of the membrane was lower in $\mathrm{M}=6$ mixture than that of $\mathrm{M}=1$ and $\mathrm{M}$ $=3$.

\section{Comparison of lactic acid conversion and reactor productivity results}

Table 2 shows brief conversion results and productivity of free and immobilized enzymes in the significant operating parameters. The highest conversion result in the BCMR was achieved as 0.63 by using RM1 membrane when the molar ratio was three and the temperature $50{ }^{\circ} \mathrm{C}$.

At the same conditions, 0.36 and 0.37 conversion results were obtained in the batch reactor with the free and immobilized lipase, respectively. After six hours, almost the same conversion and enzyme productivity were obtained by free and immobilized catalyst.
Productivity was calculated from the produced amount of ethyl lactate per amount of enzyme. In fact, the conversion obtained by immobilized lipase was higher, since the membrane simultaneously absorbed the produced water during the reaction. Thus, the idea of reducing the lipase productivity using the immobilization technique could not always be accurate. Immobilization of lipase on a thin membrane film prevented the possible agglomeration, which was proved by SEM and AFM analysis. Moreover, it was easy to recycle and reuse the immobilized lipase without significant activity loss during the six experiments.

Figure 9 presents the reusability tests of lipasecoated membrane in BCMR. The same RM1 membrane was used about six times to produce ethyl lactate at $50^{\circ} \mathrm{C}$ when the alcohol-to-acid molar ratio was one. When the catalytic activity of firstly used membrane in BCMR was defined as $100 \%$, after six experiments it preserved its catalytic activity about $90 \%$. 


\section{Conclusions}

This study focused on the efficient ethyl lactate production in an innovative BCMR system and the results were compared with the batch reactor data. In the BCMR, better conversion results were obtained as 0.63 at $50{ }^{\circ} \mathrm{C}$ when the alcohol-to-acid molar ratio was one. Under the same operating conditions, conversion of the batch reaction with immobilized enzyme was 0.37 . When the alcohol-to-acid molar ratio increased from one to three, and temperature decreased from $50{ }^{\circ} \mathrm{C}$ to $30{ }^{\circ} \mathrm{C}$, obtained conversion was 0.58 in BCMR. These results are very promising for an lipase-catalyzed ethyl lactate reaction. In the literature, relatively low conversion values were obtained under the same operating conditions, as mentioned earlier.

\section{ACKNOWLEDGEMENTS}

This study was financially supported by the Scientific and Technological Research Council of Turkey (TUBITAK)(Grant Number: 213 M 625) and the Scientific Project Center of Kocaeli University (Grant Number 2013/075).

\section{Nomenclature}

\section{Abbreviations}

$\begin{array}{ll}\text { BCMR } & - \text { Biocatalytic membrane reactor } \\ \text { RM } & - \text { Rhizomucor miehei lipase } \\ \text { PV } & - \text { Pervaporation } \\ \text { PVBCMR } & - \text { Pervaporation biocatalytic membrane re- } \\ & \text { actor } \\ \text { VOC } & - \text { Volatile organic compound } \\ \text { AFM } & - \text { Atomic force microscope } \\ \text { GC } & - \text { Gas chromatography }\end{array}$

\section{Symbols}

A $\quad$ - Effective membrane area, $\mathrm{m}^{2}$

$J \quad-$ Flux, $\mathrm{kg} \mathrm{m}^{-2} \mathrm{~h}^{-1}$

M - Alcohol-to-acid mole ratio

$M_{p} \quad$ - Weight of permeate sample, $\mathrm{kg}$

$n_{A o,} n_{A} \quad$ - Initial and final mole of lactic acid respectively, mol

$t \quad-$ Reaction time, $\mathrm{h}$

$W_{s} \quad-$ Weight of analyzed sample, $\mathrm{g}$

$X \quad-$ Lactic acid conversion

$X_{a, b} \quad$ - Mass fraction of water and other components in the permeate

$Y_{a, b} \quad-$ Mass fraction of water and other components in the permeate

$\alpha \quad-$ Separation factor

\section{References}

1. Yamaguchi, S., Tanha, M., Hult, A., Okuda, T., Ohara, H., Kobayashi, S., Green polymer chemistry: Lipase-catalyzed synthesis of bio-based reactive polyesters employing itaconic anhydride as a renewable monomer, Polym. J. 46 (2014) 2.

doi: http://dx.doi.org/10.1038/pj.2013.62

2. Koga, H., Kitaoka, T., Isogai, A., Paper-immobilized enzyme as a green microstructured catalyst, J. Mater. Chem. 22 (2011) 11591. doi: http://dx.doi.org/10.1039/C2JM30759F

3. Hobden, R., Effectiveness of ultrafiltration on the recovery and reuse of liquid enzymes in the production of biodiesel. Master dissertation, Appalachian State University, 2013.

4. Steele, B., Raj, S., Nghiem, J., Stowers, M., Enzyme recovery and recycling following hydrolysis of ammonia fiber explosion-treated corn stover, Applied Biochemistry and Biotechnology 121 (2005) 901.

doi: http://dx.doi.org/10.1385/ABAB:124:1-3:0901

5. Zhou, L. Y., Wang, C., Jiang, Y. J., Gao, J., Immobilization of papain in biosilica matrix and its catalytic property, Chin. J. Chem. Eng. 21 (2013) 670. doi: http://dx.doi.org/10.1016/S1004-9541(13)60528-5

6. Jiang, H. G., Yang, Z. J., Zhou, X. T., Fang, Y. X., Ji, H. B., Immobilization of $\beta$-cyclodextrin as insoluble $\beta$-cyclodextrin polymer and its catalytic performance, Chin. J. Chem. Eng. 20 (2012) 784. doi: http://dx.doi.org/10.1016/S1004-9541(11)60249-8

7. $L i, Y$., $H u$, J., Han, $P$., Synthesis of magnetically modified palygorskite composite for immobilization of Candida $s p$. 99-125 lipase via adsorption, Chin. J. Chem. Eng. 23 (2015) 822 .

doi: http://dx.doi.org/10.1016/j.cjche.2015.02.002

8. Marpani, F., Luo, J., Mateiu, R. V., Meyer, A. S., Pinelo, M., In situ formation of a biocatalytic alginate membrane by enhanced concentration polarization, ACS Appl. Mater. Interfaces 7 (2015) 17682.

doi: http://dx.doi.org/10.1021/acsami.5b05529

9. Gupta, S., Bhattacharya, A., Murthy, C. N., Tune to immobilize lipases on polymer membranes: Techniques, factors and prospects, Biocatal. Agric. Biotechnol. 2 (2013) 171. doi: http://dx.doi.org/10.1016/j.bcab.2013.04.006

10. Wang, Y., Hsieh, Y., Immobilization of lipase enzyme in polyvinyl alcohol (PVA) nanofibrous membranes, J. Membr. Sci. 309 (2008)73. doi: http://dx.doi.org/10.1016/j.memsci.2007.10.008

11. Wang, Y., Xu, J., Luo, G., Dai, Y., Immobilization of lipase by ultrafiltration and cross-linking onto the polysulfone membrane surface, Bioresour. Technol. 99 (2008) 2299. doi: http://dx.doi.org/10.1016/j.biortech.2007.05.014

12. Jochems, P., Satyawali, Y., Diels, L., Dejonghe, W., Enzyme immobilization on/in polymeric membranes: Status, challenges and perspectives in biocatalytic membrane reactors (BMRs), Green Chem. 13 (2011) 1609.

doi: http://dx.doi.org/10.1039/C1GC15178A

13. Draghici, C., Kowal, J., Darjan, A., Meier, W., Palivan, C. G., "Active Surfaces" formed by immobilization of enzymes on solid-supported polymer membranes, Langmuir 39 (2014) 11660. doi: http://dx.doi.org/10.1021/la502841p

14. Pereira, E. B., Zanin, G. M., Castro, H. F., Immobilization and catalytic properties of lipase on chitosan for hydrolysis and esterification reactions, Braz. J. Chem. Eng. 20 (2003) 343.

doi: http://dx.doi.org/10.1590/S0104-66322003000400002 
15. Fang, Y., Huang, X. J., Chen, P. C., Xu, Z. K., Polymer materials for enzyme immobilization and their application in bioreactors, BMB Rep. 44 (2011) 87. doi: http://dx.doi.org/10.5483/BMBRep.2011.44.2.87.

16. Hilal, N., Kochkodan, V., Nigmatullin, R., Goncharuk, V., Al-Khatib, L., Lipase-immobilized biocatalytic membranes for enzymatic esterification: Comparison of various approaches to membrane preparation, J. Membr. Sci. 268 (2006) 198 .

doi: http://dx.doi.org/10.1016/j.memsci.2005.06.039

17. Cheirsilp, B., Jeamjounkhaw, P., H-Kittikun, A., Optimizing an alginate immobilized lipase for monoacylglycerol production by the glycerolysis reaction, Journal of Molecular Catalysis B: Enzymatic 59 (2009) 206.

doi: http://dx.doi.org/10.1016/j.molcatb.2009.03.001

18. Lu, Y., X., Cai, M. Y., Guo, S. Y., Wang, Z. M., The preparation of immobilized lipase by embedded in sodium alginate, Modern Food Science and Technology 1 (2007).

19. Queiroz, A. A. A., Passos, E. D., Alves, S. B., Silva, G. S., Higa, O. Z., Vitolo, M., Alginate-Poly(vinyl alcohol) coreshell microspheres for lipase immobilization, Journal of Applied Polymer Science 102 (2006) 1553 doi: http://dx.doi.org/10.1002/app.23444

20. Won, K., Kim, S., Kim, K. J., Park, H. W., Moon, S. J., Optimization of lipase entrapment in Ca-alginate gel beads, Process Biochemistry 40 (2005) 2149. doi: http://dx.doi.org/10.1016/j.procbio.2004.08.014

21. Karla, A. B., Flavio, M. L., Fabio, Y., Katia, F. F., Lipase entrapment in PVA/Chitosan biodegradable film for reactor coatings, Mater. Sci. Eng. C 33 (2013) 1696. doi: http://dx.doi.org/10.1016/j.msec.2012.12.082

22. Dong, L. C., Wang, G., Xiao, Y., Xu, Y., Zhou, X., Jiang, H., Luo, $Q$., Immobilization of glucose oxidase on a novel crosslinked chitosan support grafted with L-lysine spacers, Chem. Biochem. Eng. Q. 25 (2011) 395.

23. Huang, X. J, Ge, D., Xu, Z. K., Preparation and characterization of stable chitosan nanofibrous membrane for lipase immobilization, Eur. Polym. J. 42 (2007) 3710. doi: http://dx.doi.org/10.1016/j.eurpolymj.2007.06.010

24. Dongzhi, W., Chunang, G., Qingxun, S., Wu, S., Enzymatic esterification for glycoside lactate synthesis in organic solvent, Enzyme Microb. Technol. 33 (2003) 508. doi: http://dx.doi.org/10.1016/S0141-0229(03)00156-X

25. Rachna, D., Datta, M., Esterification in organic solvents by lipase immobilized in polymer of PVA-alginate-boric acid, Process Biochem. 41 (2006) 951. doi: http://dx.doi.org/10.1016/j.procbio.2005.10.019

26. Trusek-Holownia, A., Noworyta, A., An integrated process: Ester synthesis in an enzymatic membrane reactor and water sorption, J. Biotechnol. 130 (2007) 47. doi: http://dx.doi.org/10.1016/j.jbiotec.2007.03.006

27. Rios, G. M., Belleville, M. P., Paolucci, D., Sanchez, J., Progress in enzymatic membrane reactors - A review, J. Membr. Sci. 242 (2004) 189. doi: http://dx.doi.org/10.1016/j.memsci.2003.06.004

28. Hilal, N., Nigmatullin, R., Alpatova, A., Immobilization of cross-linked lipase aggregates within microporous polymeric membranes, J. Membr. Sci. 238 (2004) 131. doi: http://dx.doi.org/10.1016/j.memsci.2004.04.002

29. Findrik, Z., Nemeth, G., Vasic-Racki, D., Belafi-Bako, K., Csanadi, Z., Gubicza, L., Pervaporation-aided enzymatic esterifications in non-conventional media, Process Biochem. 47 (2012) 1715. doi: http://dx.doi.org/10.1016/j.procbio.2012.08.003
30. Major, B., Nemestóthy, N., Bélafi-Bakó, K., Gubicza, L., Enzymatic esterification of lactic acid under microwave conditions in ionic liquids, Hungarian J. Ind. Chem. 36 (2008) 77 .

31. Hasegawa, S., Azuma, M., Takahashi, K., Enzymatic esterification of lactic acid, utilizing the basicity of particular polar organic solvents to suppress the acidity of lactic acid, J. Chem. Technol. Biotechnol. 83 (2008) 1503. doi: http://dx.doi.org/10.1002/jctb.1935

32. Sun, J., Jiang, Y., Zhou, L., Gao, J., Optimization and kinetic study of immobilized lipase-catalyzed synthesis of ethyl lactate, Biocatal. Biotransform. 28 (2010) 279. doi: http://dx.doi.org/10.3109/10242422.2010.501893

33. Ozdemir, S. S., Buonomenna, M. G., Drioli, E., Catalytic polymeric membranes: Preparation and application, Appl. Catal. A. 307 (2006) 167. doi: http://dx.doi.org/10.1016/j.apcata.2006.03.058

34. Caetano, C. S., Guerreiro, L., Fonsec, I. M., Ramos, A. M., Vital, J., Castanheiro, J. E., Esterification of fatty acids to biodiesel over polymers with sulfonic acid groups. Appl. Catal. A. 359 (2009) 41. doi: http://dx.doi.org/10.1016/j.apcata.2009.02.028

35. Temoçin, Z., Covalent immobilization of Candida rugosa lipase on aldehyde functionalized hydrophobic support and the application for synthesis of oleic acid ester, J. Biomater. Sci. Polym. Ed. 24 (2013) 1618. doi: http://dx.doi.org/10.1080/09205063.2013.786970

36. Ugur Nigiz, F., Hilmioglu, N. D., Green solvent synthesis from biomass based source by biocatalytic membrane reactor, Int. J. Energy Res. 40 (2016) 71. doi: http://dx.doi.org/10.1002/er.3319

37. Findrik, Z., Nemeth, G., Gubicza, L., Vasic-Racki, D., Bela$f i-B a k o, K$., Evaluation of factors influencing the enantioselective enzymatic esterification of lactic acid in ionic liquid, Bioprocess Biosyst. Eng. 35 (2012) 625. doi: http://dx.doi.org/10.1007/s00449-011-0645-5

38. Koutinas, M., Menelaou, M., Nicolaou, E. N., Development of a hybrid fermentation-enzymatic bioprocess for the production of ethyl lactate from dairy waste, Bioresource Technology 165 (2014) 343. doi: http://dx.doi.org/10.1016/j.biortech.2014.03.053

39. Asthana, N., Kolah, A., Vu, D. T., Lira, C. T., Miller, D. J., A continuous reactive separation process for ethyl lactate formation, Organic Process Research \& Development 9 (2005) 599. doi: http://dx.doi.org/10.1021/op0500640

40. Zhang, S., Shang, W., Yang, X., Zhang, S., Zhang, X., Chen, $X$., Immobilization of lipase using alginate hydrogel beads and enzymatic evaluation in hydrolysis of p-nitrophenol butyrate, Bull. Korean Chem. Soc. 34 (2013) 2741. doi: http://dx.doi.org/10.5012/bkcs.2013.34.9.2741

41. Baker, R. W., Membrane Technology and Applications. John Wiley \& Sons Ltd, Chichester, England, 2004. doi: http://dx.doi.org/10.1002/0470020393

42. Zhang, Q. Y., Wu, J. F., Ma, P. H., Cai, J., Zhang, Y. T., Acid value determination and preesterification of crude $E u$ phorbia lathyris L. oil, World Journal of Engineering and Technology 3 (2015) 70. doi: http://dx.doi.org/10.4236/wjet.2015.32007

43. Viele, E. L., Chukwuma, F. O., Uyigue L., Esterification of high free fatty acid crude palm kernel oil as feedstock for base-catalyzed transesterification reaction, International Journal of Application or Innovation in Engineering \& Management (IJAIEM) 2 (2013) 361. 
44. Jullok, N., Darvishmanesh, S., Luis, P., Van der Bruggen, $B$., The potential of pervaporation for separation of acetic acid and water mixtures using polyphenylsulfone membranes, Chem. Eng. J. 175 (2011) 306. doi: http://dx.doi.org/10.1016/j.cej.2011.09.109

45. Nunes, S. P., Peinemann, K. V., Membrane Technology in the Chemical Industry, Wiley, Germany, 2006. doi: http://dx.doi.org/10.1002/3527600388

46. Wu, H., Zhou, T., Li, X., Zhao, C., Jiang, Z., Enhancing the separation performance by introducing bioadhesive bonding layer in composite pervaporation membranes for ethanol dehydration, Chin. J. Chem. Eng. 23 (2015) 372. doi: http://dx.doi.org/10.1016/j.cjche.2014.11.022

47. Cruz-Ortiz, B. R., Ríos-González, L. J., García, Y. G., Garza, J. A. R., Rodríguez-Martínez, J., Immobilization of Thermomyces lanuginosus lipase in PVA-alginate beads, J. Mex. Chem. Soc. 55 (2011) 176.

48. Kwon, S. J., Song, K. M., Hong, W. H., Rhee, J. S., Removal of water produced from lipase-catalyzed esterification in organic solvent by pervaporation, Biotechnol. Bioeng. 46 (1995) 393. doi: http://dx.doi.org/10.1002/bit.260460413

49. Bako, K. B., Dörmo, N., Ulbert, O., Gubicza, L., Application of pervaporation for removal of water produced during enzymatic esterification in ionic liquids, Desalination 149 (2002) 267

doi: http://dx.doi.org/10.1016/S0011-9164(02)00781-6

50. Fen, G. W., Pervaporation Study of Butanol/Water Mixtures by PVA and Polyimide Membranes, PhD Thesis, National University of Singapore (2005) 1-75.

51. Nigiz, F. U., Hilmioglu, N. D., Pervaporation of ethanol/ water mixtures by zeolite filled sodium alginate membrane, Desalin. Water Treat. 51 (2013) 637. doi: http://dx.doi.org/10.1080/19443994.2012.714582

52. Nigiz, F. U., Dogan, H., Hilmioglu, N. D., Pervaporation of ethanol/water mixtures using clinoptilolite and 4A filled sodium alginate membranes, Desalination 300 (2012) 24. doi: http://dx.doi.org/10.1016/j.desal.2012.05.036

53. Shah, S. D., Pervaporation of solvent mixtures using polymeric and zeolitic membranes: Separation studies and modeling, PhD Thesis, University of Kentucky (2001) 21-24.

54. Boddeker, K. W., Liquid Separations with Membranes: An Introduction to Barrier Interference, Springer Berlin Heidelberg New York, 2008.

55. Smitha, B., Suhanya, D., Sridhar, S., Ramakrishna, M., Separation of organic-organic mixtures by pervaporation-A review, Journal of Membrane Science 241 (2004) 1. http://dx.doi.org/10.1016/j.memsci.2004.03.042 